\title{
Research on the Construction of Logistics Financial Model based on System Dynamics
}

\author{
Bo Sun ${ }^{1}$, Haotian Liu ${ }^{2}$ \\ ${ }^{1}$ Shandong Youth University of Political Science, School of Economics and Management, Jinan, \\ Shandong, 250000 \\ ${ }^{2}$ Agricultural Bank of China Shandong Branch, Jinan, Shandong, 250000
}

Keywords: Logistics Financial Model, System Dynamics, Models Construction

\begin{abstract}
Supply chain finance is an innovative service that integrates financial service and logistics service. The business is rooted in the real transaction in the supply chain, which can realize the win-win situation among SMEs, financial institutions and logistics enterprises. It solves the financing difficulties of SMEs, The risk of financing services to financial institutions, while bringing new profit growth point of logistics enterprises. Therefore, the short-term supply chain finance in China has made rapid development. However, because the business involves a variety of formats of coordination and cooperation, and China is facing the development of industry and enterprise levels of two imbalances, so the system can not achieve the internal coordination of the state, leading to the development of domestic supply chain financial system, there are many problems. How to solve these problems effectively and ensure the orderly state of time, space and function between subsystems and elements is the focus of academic research.
\end{abstract}

\section{Introduction}

SME financing has always been a difficult problem, the industry well-known magazine has been the development of SMEs in the bottleneck problems easily conducted a social survey, the results of more than one-third of the respondents said that financing is to restrict the development of small and medium enterprises One of the important factors. In contrast to the significant contribution of SMEs to the national economy, their financing channels are narrow and their proportion in the total financial credit is not high. Out of the cost of capital considerations, small and medium enterprises have always bank credit funds as the preferred financing channels, followed by its own capital and private financing. However, such enterprises have not been the attention of financial institutions, the smaller the scale of enterprises, the lower the success rate of loan applications. A survey of SME loans shows that respondents in 2011 only 53\% of the loan application through the part of the 41\% of enterprises in the financing time of three weeks or more, the lending rate is less than the funding gap Speed, can not meet the daily business needs of SMEs.

The emergence of the supply chain financial business, the problem gradually resolved, the predecessor of the domestic supply chain financial business first appeared in the Ping An Bank (formerly Shenzhen Development Bank), even if the classic "1 + N" paradigm financing model, In 2006, China launched the "Supply Chain Finance" business for SMEs for the first time. The major banks have also launched their own supply chain financing products, the market response is good, high economic efficiency, which also makes the government departments pay more attention to the development of supply chain finance. 


\section{The Dynamic Mechanism of Collaborative Optimization in Supply Chain Finance}

Competition in the supply chain financial system refers to the competition activities and processes between different systems, between different subsystems and between the elements within the system, in order to obtain the dominant position and the right to speak. Competition within the system and the system is a basic contact, through competition, the system elements and subsystems to achieve survival of the fittest, the elements of survival in the competition to adapt to the entire system of long-term development, and promote its continuous evolution, to a more orderly direction. In the supply chain financial system, there are two main forms of competition, namely, competition between different systems and the same system within the subsystems or elements of competition. On the one hand, in order to maintain the dynamic stability and orderly development of its own system, the supply chain financial system needs to exchange with the outside constantly for logistics, capital flow and information flow. However, due to the scarcity of resources in the social system as a whole, different systems must compete to obtain limited social resources, such as limited SME customer resources in a certain period of time. On the other hand, the supply chain financial system in order to better adapt to the external environment requirements, the various subsystems within the system will be based on environmental characteristics of spontaneous endogenous regulation and innovation in order to improve the adaptability of their systems to the environment, and these adjustments and Innovation often occurs in the form of competition, and the competition between subsystems promotes the development and perfection of the whole system. For example, banks can increase the strength of the banking subsystem within the financial system by introducing different financing products to meet the financing needs of all types of enterprises.

There is also competition among subsystems of different systems. At the same time, many enterprises in the whole social system provide the same or similar services. For example, logistics enterprises, the scarcity of professional logistics personnel, logistics infrastructure and preferential policies, etc., are subsystems between the incentives. The survival of the fittest of competition makes the excellent subsystem survive, and promote the optimization of the whole supply chain financial system.

In short, competition for an open system is absolute, on the one hand through the survival of the fittest to optimize the allocation of resources, so that the optimal resources are the most competitive elements of the system owned or controlled to improve the strength and winners Economic benefits; on the other hand through the hoof of the system elements and the original system structure to break and re-combination, optimizing the entire system to improve the system's ability to adapt to the environment. Therefore, competition is one of the driving forces for the coordinated development of the system.

\section{Collaborative Strategy of Supply Chain Finance System}

Government departments can choose some key industries in the development prospects of enterprises as a benchmark for the development of supply chain financial system, through the development of macroeconomic policies to change the direction of the advantages of resources through the standard Xuan enterprises to market signals, through the overall planning, guiding other Supply chain financial system to a more rational and orderly direction; the other hand, enterprises can according to their own practical experience in government policy-making process to provide valuable advice and suggestions to ensure that the policy of practicality and feasibility. In addition to the collaboration between the government and enterprises, collaboration among related industry associations is also an important aspect of resource coordination. Industry associations (including 
China Banking Association, China Logistics Association, China Small and Medium Enterprises Association and China Storage Industry Association), which are the main elements of the supply chain financial system, can formulate targeted industry norms through mutual communication and exchange. And the system, for the supply chain finance to the development of orderly direction to provide certain industry norms and system support.

Supply chain financial system of enterprises and systems outside the universities and research institutes of the collaboration is also very important. This cooperation can achieve a win-win situation, on the one hand elements of the supply chain financial system enterprises can make full use of universities and research institutes in the scientific and technological resources for the coordinated development of the entire system to provide theoretical and technical support; the other hand, And scientific research institutes can carry out the theoretical research with the cooperative projects carried out by enterprises and provide the theoretical basis for the development of supply chain financial system.

Management activities involving planning, organization, leadership and control and other links, so the scope of management and coordination is also more extensive. According to the management activities, this paper divides management coordination into three aspects: target collaboration, organization collaboration, system and process coordination.

To realize the management and coordination of the supply chain financial system, it is necessary to combine the whole and part of the two levels: First, the overall level, the supply chain financial system as a mutually beneficial organic whole, from the system point of view to explore the management and coordination Therefore, the relevant elements of the supply chain financial system should have the idea of systematic management. To commercial banks, for example, its internal need to set up a separate supply chain financial management department, the establishment of matching incentives and restraint mechanisms for the standardization of management. The second is part of the level, the system must be a correct understanding of the internal elements and the relationship between the system. The elements need to have a common goal based on common interests. Through the cooperation among the elements, the system can realize the function which can not be realized by the independent elements, so that each factor can realize its own interests. Each enterprise is a component of the supply chain financial system. The supply chain financial system is the composition of the whole social system elements, only by not self-regulation, the enterprise can adapt to different levels of the external environment, to promote the stable and orderly development of the system.

\section{Supply Chain Financial System Collaborative Operation Model}

Integrity refers to the system consists of multiple elements or subsystems, is a certain function of the organic whole. The supply chain financial system has the system integrity, is composed of different subsystems through the organic integration and mutual cooperation and organic whole, each part of the whole will affect the overall operation, the mountain part of the whole can be achieved part of the can not be achieved aims. As for the supply chain financial system, each of the main elements within the system is an integral part of the system, the relationship between the elements and the whole is the role and reaction, factor performance directly affect the overall performance, the overall performance of the elements of performance Feedback, which is mainly reflected in the two aspects of incentives and supervision, and to promote the elements in favor of the evolution of the overall direction of the system to develop. Bank risk prevention and control means of upgrading and improving the logistics enterprise information system will promote the development of the entire supply chain financial system evolution. Integrity is the system of the 
system has become the basis of the characteristics.

\section{Supply Chain Finance System Collaborative Optimization}

The system dynamics method needs to link the various elements within the system in the form of relational graph, and determine the whole boundary of the system, the way of internal elements connection, that is, the system specific result can be determined by computer simulation technology. And then through the computer language to simulate the various decision-makers decision-making, this one can be predicted by the future behavior of the overall system for the participants to provide strategic guidance, the two can help participants at the specific level to make the best decision making. Based on VENSIM PLE, this paper establishes the corresponding system dynamics model. System dynamics approach to the internal system and you can specifically analyze the feedback structure between the internal variables in the system, so as to study the overall level of system behavior. Using this method to study the supply chain financial system, can provide dynamic feedback structure of the system to facilitate the analysis of the relationship between variables within the system. The model can show the dynamic change of the system, establish the model according to the logical relationship between the variables and the historical data. Through the dynamic feedback mechanism of the model, analyze the relationship among variables, and forecast the future results. It can provide the number and structure of the decision- On the relevant basis.

China's economy is in a period of rapid development, which for the economic system of each individual, while bringing opportunities and challenges. The entire supply chain can increase the volume in the trading volume of profit; of course, the volume of transactions for small and medium enterprises can bring business to upgrade, they also have to pay a lot of hot money liquidity, financing difficulty gains, The risk of fracture increases. SME financing difficulties will be the first obstacle

Its own development, and then will drag the entire supply chain and making the supply chain has a competitive advantage in the core business also had to slow down the pace of development. Supply chain finance as an innovative financial model, can help SMEs get rid of the dilemma of financing difficulties. Financing Modes the supply chain financial model can be divided into the Confirmed Warehouse model (based on the prepayment model), the Accounts Receivable Model (based on the Accounts Receivable model), and the Finance Warehouse in different positions in the supply chain according to the funding gap Mode (inventory-based model). The healthy and orderly development of supply chain finance can provide financing support for small and medium-sized enterprises, and promote the development of the whole supply chain.

\section{Conclusion}

Based on the analysis of the supply chain financial system, this paper further explores the system of collaborative development. The synergetic development of the supply chain financial system includes two dimensions: internal coordination and external coordination. The former refers to the coordination and synchronization between the various factors within the system and the same target; the latter refers to the continuous adjustment and adaptation of the external macro environment. Based on this, this paper analyzes the target of coordinated development of the system and the economic benefit of the order parameter, the process of the coordinated development of the system the dynamic mechanism of self-organization and organization and system coordination development - competition and cooperation, the content of coordinated development of the system And mode of operation. 


\section{References}

[1] Guo Anyuan. Excellent application of soft science thought - take Shenzhen Development Bank's financial business innovation management as an example [J]. China Soft Science, 2009 (12)

[2] Feng Jingsheng. Supply chain finance: advantages, risks and recommendations [J]. Journal of Regional Finance, 2009 (02)

[3] Zou Huixia, Long Zhijun.Study on producer inventory control mechanism based on system dynamics [J]. Journal of Wuhan University of Technology (Information \& Management Engineering), 2007 (10)

[4] Qian Qinghong. Reflections on the Financing of Small and Medium-sized Enterprises in China [J]. Acta Finance and Accounting Research, 2007 (08)

[5] Xu Xin. Interpretation of the dual mode of supply chain financing [J]. Logistics Technology, 2007 (07) 